\title{
Effects of Prior Fluoxetine Treatment on EEG Sleep in Women with Recurrent Depression
}

\author{
Daniel J. Buysse, M.D., David J. Kupfer, M.D., Christine Cherry, M.S., Deborah Stapf, B.A.,
} and Ellen Frank, Ph.D.

We examined whether fluoxetine treatment has
persistent effects on electroencephalographic sleep after
drug discontinuation in patients with recurrent major
depression. Age-matched groups of 23 women were treated
with interpersonal psychotherapy alone (IPT) or fluoxetine
plus interpersonal psychotherapy (IPT + FLU). Sleep
studies were conducted when patients were depressed, and
again at remission, at least four weeks after fluoxetine
discontinuation. The groups did not differ in depression
ratings pre- to post-treatment. Significant grouptime
interaction effects were noted for REM sleep (p $=.04)$ and slow wave sleep $(\mathrm{p}=.02)$. REM percentage and phasic REM activity increased in the IPT + FLU group but decreased in the IPT group. The effects of fluoxetine treatment on electroencephalographic sleep can be observed for at least four weeks after drug discontinuation and appear to represent both drug discontinuation and neuroadaptation effects.

[Neuropsychopharmacology 21:258-267, 1999] (C) 1999 American College of Neuropsychopharmacology. Published by Elsevier Science Inc.
KEY WORDS: Sleep; Depression; Fluoxetine;

Drug discontinuation; Treatment

Antidepressant drugs have effects on both subjective and polysomnographic (PSG) measures (Sharpley and Cowen 1995; Thase 1998). Fluoxetine, one of the serotonin reuptake inhibitors, has been well-characterized in this regard. Single doses cause a dose-dependent increase in wakefulness in healthy subjects when administered at night (Nicholson and Pascoe 1988), but not in the morning or evening (Saletu et al. 1991; von Bardeleben et al. 1989). Dose-dependent insomnia and other

From the Depression and Manic Depression Prevention Program and the Sleep and Chronobiology Center, Western Psychiatric Institute and Clinic, University of Pittsburgh School of Medicine, Pittsburgh, PA.

Address correspondence to: Dr. Buysse, E-1127 WPIC, 3811 O'Hara St., Pittsburgh, PA 15213.

A preliminary version of these results was presented at the Association of Professional Sleep Societies annual meeting, 1997.

Received October 26, 1998; revised January 11, 1999; accepted February 16, 1999. "activating" side effects occur in approximately $25-40 \%$ of depressed patients treated with fluoxetine (Beasley et al. 1992), even though recovered patients overall report decreased sleep disturbance relative to their depressed baseline (Satterlee and Faries 1995; Armitage et al. 1997a; Gillin et al. 1997). Fluoxetine is also associated with modest reductions in sleep efficiency, rapid eye movement (REM) sleep percentage, and stage $3 / 4$ nonrapid eye movement (NREM) sleep percentage, and with increases in wakefulness, Stage 1 NREM sleep percentage, and the number of eye movements during REM sleep (Armitage et al. 1997a; Gillin et al. 1997; Stokes 1995; Hendrickse et al. 1994; Kerkhofs et al. 1990). Other PSG effects noted with fluoxetine include periodic limb movements and prominent eye movements during NREM sleep (Schenck et al. 1992; Armitage et al. 1995; Dorsey et al. 1996).

Fluoxetine's long elimination half-life and its effects on serotonergic neurotransmission raise the possibility of persistent effects on PSG findings and the neurobiological systems which regulate sleep and wakefulness, 
even after the drug has been discontinued. Uncontrolled studies have indeed suggested that some PSG effects of fluoxetine may persist for up to 19 months after discontinuation (Schenck et al. 1992; Winkelman et al. 1992), but no controlled studies have been performed. It is difficult to know from these reports whether sleep changes associated with prior fluoxetine treatment actually represent persistent effects of the drug, discontinuation effects, or some form of neuroadaptation caused by prior drug administration. A better understanding of these possibilities is important for two reasons. First, patients previously treated with fluoxetine may present with sleep complaints which may or may not be related to their prior treatment. Second, it is important to know how prior drug treatment may affect physiological measures among patients who require procedures for clinical or research studies. For example, a previous study suggested that a 7-14 day "washout" period was adequate when performing sleep studies on patients previously treated with tricyclic antidepressants (Lauer and Pollmacher 1992), but this guideline may not hold true for patients treated with other medications such as fluoxetine.

The present controlled study was conducted to better understand the effects of fluoxetine exposure on women with major depressive disorder (MDD). Specifically, we examined clinical and PSG measures at baseline, when patients were depressed, and again at recovery, when they were not depressed. Patients were treated successfully with a combination of fluoxetine and interpersonal psychotherapy (IPT), but the medication was discontinued at least four weeks prior to the second set of PSG studies; thus, both sets of PSG studies were conducted when patients were medication-free. To control for effects related to clinical state, we compared changes in clinical and PSG measures among the fluoxetine-treated patients to the same measures in a control group of age-matched women treated successfully with IPT alone. The aim of this study was primarily a descriptive one, because it seemed plausible that prior fluoxetine treatment could produce either persistent effects on PSG sleep (e.g., sleep continuity disturbance, REM sleep suppression) or discontinuation effects (e.g., increase in REM sleep).

\section{METHODS}

The results reported here are one component of a study investigating the efficacy of three "doses" of IPT as a maintenance treatment for recurrent major depressive disorder (MDD) in women (MH 49115, E. Frank, Principal Investigator). The study design involves acute open treatment with IPT until patients remit from the index episode. Patients who do not recover with IPT alone are treated with a combination of IPT plus fluoxetine until remission and for five months of continuation treatment, at which time the medication is tapered and discontinued. Patients in IPT alone and IPT plus fluoxetine groups are then randomly assigned to weekly, biweekly, or monthly maintenance IPT for two years. Recurrence rates and time to recurrence constitute the major outcome variables for the parent study. In order to examine biological correlates of clinical course in these patients, we conduct PSG studies at baseline (while depressed), at remission, and at the end of maintenance treatment. Data from the final set of studies are not included in this report because the treatment trial is ongoing.

\section{Patients}

Subjects included in the current report are 46 women with recurrent MDD without psychotic features who were recruited, studied, and treated as outpatients. These patients comprise two age-matched groups: One group successfully treated with IPT alone (IPT group), and one group who did not respond to IPT alone, but who did respond to combination treatment with fluoxetine plus IPT (IPT + FLU group). The IPT + FLU group consisted of all available consecutive patients treated successfully with this modality. Patients from the IPT group were selected on the basis of age matching to patients in the IPT + FLU group. All patients were required to have at least one previous episode of MDD occurring no more than 2.5 years prior to the index episode, with a complete symptomatic remission lasting at least 10 weeks between episodes. Diagnoses were established initially using the Schedule for Affective Disorders and Schizophrenia (Endicott and Spitzer 1978) and subsequently using Structured Clinical Interview for DSM-III-R or DSM-IV (Spitzer et al. 1988; Spitzer et al. 1992; First et al. 1995) administered by masters' level psychiatric clinicians. All patients were required to meet a severity threshold of a score $\geqslant 15$ on the 17-item Hamilton Rating Scale for Depression (HRSD) (Hamilton 1967) and a score $\geqslant 7$ on the Raskin Scale (Raskin et al. 1969). Patients were excluded for most other Axis I psychiatric diagnoses, for substance abuse/dependence within the previous three years, or if they met full criteria for antisocial or borderline personality disorder. We did accept patients with generalized anxiety disorder, panic disorder, eating disorder NOS, and subsyndromal borderline or antisocial personality features, as long as recurrent MDD was the primary diagnosis. In addition, patients were evaluated with a medical history and physical examination in order to verify that they had no acute or unstable medical problems, and were taking no medications which would cause mood or sleep symptoms. Patients had sleep studies only if they maintained a regular sleepwake schedule with no rotating or night shift work, as 
determined by self-report and/or sleep-wake diaries. Subjective sleep quality at baseline was assessed using the Pittsburgh Sleep Quality Index (Buysse et al. 1989). Finally, patients were medication-free of all psychotropic medications for at least two weeks prior to sleep studies. A total of six patients in the IPT group and four patients in the IPT + FLU group had been treated previously with serotonin reuptake inhibitors (SRI). The most recent SRI exposure was six weeks prior to sleep studies in two patients in the IPT + FLU group (one treated with fluoxetine and one with sertraline). Six patients in the IPT group and four in the IPT + FLU group had previously been treated with other antidepressants, with the most recent exposure being more than two weeks prior to sleep studies (one patient in the IPT group treated with nortriptyline).

\section{Treatment Protocol}

All patients were treated initially with IPT (Klerman et al. 1984) without pharmacotherapy until remission of their episode or until a determination of non-response was made. Treatment consisted of weekly IPT sessions with a master's or doctoral level clinician, trained by a certified IPT trainer (Cleon Cornes, M.D.). Weekly HRSD ratings were performed by a clinician other than the patient's therapist. Periodic reliability checks have shown an intraclass correlation of 0.94 for the HRSD total score across seven patients and 14 raters. If HRSD scores did not decrease by $\geqslant 33 \%$ within the first four weeks, sessions were increased to twice weekly. Remission was defined by a HRSD score $\leqslant 7$ and a Raskin score of $\leqslant 5$ for three consecutive weeks, by clinical consensus, and by a minimum of 12 weeks of IPT. In general, patients were treated for 12-20 weeks on a weekly basis to reach remission. Treatment nonresponse was defined by the following criteria: Failure to remit within six months (24 weeks); failure to show even a modest response to psychotherapy (less than 25\% symptom reduction from baseline HRSD by week 6; less than $50 \%$ reduction by week 12 ; or less than $50 \%$ symptom reduction after four weeks of weekly IPT, followed by 4 weeks of twice per week IPT); or a relapse during continuation treatment, defined as an HRSD score $\geqslant 15$ for two consecutive weeks following remission. Patients who met criteria for nonresponse were treated with continued IPT plus fluoxetine. Clinical status during acute treatment was monitored with weekly HRSD and Raskin rating scales, as well as the Beck Depression Rating Scale (Beck et al. 1961) and the Global Assessment Scale (Endicott et al. 1976).

Fluoxetine treatment was conducted on an open-label, flexible-dose basis. Patients were started on 10-20 mg, and the dose increased to the level that produced the optimal balance between therapeutic effects and side effects. The mean final dose of the 23 patients was $24.8 \pm$
$13.2 \mathrm{mg}$ per day (median 20, range 5-60). Weekly IPT was continued during fluoxetine treatment. Acute treatment was continued until patients met the criteria for remission described above, then for an additional 20 weeks of continuation treatment. For patients who continued to meet remission criteria, fluoxetine was then tapered by approximately $10 \mathrm{mg}$ per week and discontinued. Recovery sleep studies were conducted a mean of $6.2 \pm 3.2$ weeks (median 5.1, range 3.7-18.7) after medication discontinuation.

Following acute and continuation treatment, patients from both IPT + FLU and IPT groups were randomly assigned to weekly, bi-weekly, or monthly maintenance therapy with IPT alone (no medication). Clinical ratings were conducted once per month in all patients. If a patient scored $\geqslant 15$ of the HRSD, a repeat rating was done the following week. Recurrence was defined by a HRSD score of $\geqslant 15$ for two consecutive weeks, and by the presence of an episode of major depression judged by an independent psychiatrist not part of the patient's treatment team.

\section{EEG Sleep Studies}

Three nights of EEG sleep studies were conducted during subjects' habitual sleep-wake times, determined by self-report and/or sleep-wake diary. Mean data from Nights 2 and 3 were used in these analyses. Data for the present report are taken from studies conducted at pretreatment baseline (while patients were depressed) and again at remission (when patients were not depressed) and after medication discontinuation in the IPT + FLU group. All patients in IPT + FLU and IPT groups were medication-free during each set of sleep studies. The standard sleep montage consisted of a single channel of EEG $\left(C_{3}\right.$ or $C_{4}$ referenced to $\left.A_{1}-A_{2}\right)$, bilateral electrooculograms (EOG) referenced to $\mathrm{A}_{1}-\mathrm{A}_{2}$, and bipolar submental electromyogram (EMG). Polysomnographic data were collected through Grass Model 78 amplifiers with filter settings of $100 \mathrm{~Hz}$ and $0.3 \mathrm{~Hz}$ for EEG and EOG, and $90 \mathrm{~Hz}$ and $10 \mathrm{~Hz}$ for EMG, and a sensitivity of $5 \mu \mathrm{V} / \mathrm{mm}$. Data were also digitized on-line at 256 $\mathrm{Hz}$, recorded and stored on PCs as previously described (Doman et al. 1995). Patients were not routinely screened for periodic limb movements or sleep apnea. However, the histories of patients who were obese or who presented with symptoms suggestive of a primary sleep disorder were discussed with the first author, and additional monitoring for apnea and periodic limb movements was ordered if indicated.

Sleep studies were visually scored in 60-second epochs by technologists who maintain high scoring reliability as indicated by mean kappa values $>0.60$ for various sleep stages. In addition, quantitative analyses of sleep data were conducted using period-amplitude analysis for EEG delta activity and a separate computer 
algorithm for identification of rapid eye movements during REM sleep (Doman et al. 1995).

\section{Statistical Analyses}

Clinical and PSG data were examined for normal distributions in all analyses, and if indicated, appropriate transformations were applied prior to statistical analyses. Baseline clinical and demographic characteristics of FLU and IPT groups were contrasted with t-tests. Repeated-measures MANOVAs were used to compare clinical and PSG measures between the two groups and across time. Specifically, MANOVAs used one between-groups factor (FLU versus IPT), one repeated measure (baseline versus recovery sleep) and the interaction of these factors (group*time). Four MANOVAs were run, representing domains of slow wave sleep, REM sleep, sleep continuity, and REM latency/ delta sleep ratio. These domains and the specific sleep measures they comprise were identified in a principal components analysis of sleep measures conducted in a larger sample of patients from this study (Buysse et al. 1998). Basically, this analysis was designed to identify groups of sleep variables which strongly correlated with each other, in order to reduce the number of univariate comparisons conducted. Each of these domains includes variables which differ among depressed patients and control subjects (Benca et al. 1992). Some of these domains, such as reduced REM latency, delta ratio, and slow wave sleep, or increased REM sleep, may also be associated with unfavorable clinical outcomes in depression (Buysse et al. 1997; Kupfer et al. 1990; Giles et al. 1987; Dew et al. 1997). For the present analyses, any significant group, time, or group*time interaction effects from the MANOVAs were then followed by univariate ANOVAs conducted on the individual sleep measures contained in that MANOVA. In order to contrast clinical and PSG measures among FLU patients who did and did not have a recurrence during mainte- nance treatment, we performed MANOVAs and ANOVAs comparing the change in clinical or sleep measures from baseline to recovery. An alpha level of 0.05 was used for all statistical tests.

\section{RESULTS}

\section{Clinical and Treatment Results}

The number of patients in this analysis was determined by the number who did not remit with IPT alone, who did remit with combined IPT and fluoxetine treatment, and who had sleep studies at baseline and remission time points. A total of 138 patients had entered the study and had an outcome in the acute treatment phase at the point in which these analyses were conducted. Of these, 71 responded to IPT alone, 11 dropped out or were terminated from the study, 55 were treated with combined medication and IPT (including three who relapsed after initial response to IPT alone), and four declined medication treatment. Fluoxetine was the drug of first choice in this study, but four patients were treated with another drug for various reasons (e.g., previous unsuccessful treatment with or intolerance to fluoxetine). Of the 51 patients who began treatment with fluoxetine, 44 had a remission of depression, five did not have a remission, and two dropped out or were terminated. Twenty-three patients successfully treated with fluoxetine also had complete PSG studies at baseline and recovery, and constitute the IPT + FLU group in these analyses. The other 21 patients treated with fluoxetine either had a relapse before maintenance sleep studies $(n=11)$, did not complete sleep studies at one or both of the time points $(n=5)$, or did not discontinue fluoxetine following continuation treatment $(n=5)$.

Table 1 indicates demographic and clinical characteristics of the IPT + FLU and IPT groups. The two groups did not differ on any of these variables except the duration of acute treatment. As expected from the study de-

Table 1. Demographic and Clinical Characteristics of IPT + FLU and IPT Groups

\begin{tabular}{lcccc}
\hline & $\begin{array}{c}\text { IPT }+ \text { FLU Group } \\
(\mathbf{n}=\mathbf{2 3}) \\
\text { Mean (S.D.) }\end{array}$ & $\begin{array}{c}\text { IPT Group } \\
\mathbf{( n = 2 3 )} \\
\text { Mean (S.D.) }\end{array}$ & t Statistic & $p$ Value \\
\hline Age & $37.3(9.1)$ & $37.3(9.1)$ & 0.00 & 1.00 \\
Age of onset of depression & $22.7(8.2)$ & $23.1(7.4)$ & 0.19 & .85 \\
Duration of index episode prior to treatment (weeks) & $32.1(23.6)$ & $28.7(22.3)$ & -0.50 & .62 \\
Number of episodes & $5.4(3.0)$ & $5.1(3.0)$ & -0.37 & .71 \\
Baseline Hamilton Rating Scale for depression, 17-item & $18.2(3.1)$ & $17.8(2.3)$ & -0.43 & .67 \\
Baseline Hamilton rating scale of depression, 25-item & $21.9(4.3)$ & $21.7(3.2)$ & -0.16 & .88 \\
Baseline Global Assessment Scale & $55.5(5.3)$ & $56.4(4.7)$ & 0.59 & .56 \\
Baseline Pittsburgh Sleep Quality Index & $9.6(3.7)$ & $7.6(3.7)$ & 1.99 & .17 \\
Education (years) & $15.3(2.1)$ & $15.8(1.9)$ & 0.97 & .34 \\
Duration of acute treatment (weeks) & $59.6(16.0)$ & $26.2(5.3)$ & 3.66 & .0001 \\
\hline
\end{tabular}


sign, the IPT + FLU group had a longer duration of acute treatment than the IPT group $(p=.0001)$.

\section{Clinical and Sleep Changes Between Baseline and Recovery}

Table 2 shows the results of repeated-measures ANOVAs for clinical measures, and repeated-measures MANOVAs for the four sleep domains. A significant decrease in HRSD and PSQI scores was identified from baseline to recovery, confirming improvements in depressive symptoms and sleep quality with successful treatment. The IPT + FLU and IPT groups did not respond differently to treatment, nor did either group have more severe symptoms, as indicated by the absence of significant group ${ }^{*}$ time and group effects in the ANOVA.

MANOVAs on the four sleep domains indicated that the groups had different patterns of change from baseline to recovery in terms of slow wave sleep $(p=.02)$ and REM sleep $(p=.04)$, as indicated by significant group*time interaction effects. In addition, there was a main effect for time in the REM factor $(p=.01)$. No significant group, time, or group time interaction effects were noted for sleep continuity or REM latency/delta ratio factors.

ANOVAs for individual sleep variables within the slow wave sleep and REM domains are shown in Table 3. These results showed a tendency for quantitative measures of delta activity to increase and for Stage 2 to decrease in the IPT + FLU group, with little change evident on any of these measures in the IPT group. However, none of the univariate tests of slow wave sleep variables showed significant group*time, group, or time effects. Within the REM domain a consistent pat- tern emerged, characterized by increases in phasic REM activity and REM percentage from baseline to recovery in the IPT + FLU group, and no change or decreases in the same measures for the IPT group. Significant group*time effects were identified for five of the seven variables within the REM sleep domain. Figure 1 illustrates these interactions for visually-scored percentage REM and automated REM counts over the entire night. In addition to these interaction effects, significant main effects for group and for time were identified for REM sleep percentage, automated REM counts for the whole night, and automated REM counts in the first REM period. These main effects indicate higher values in the IPT + FLU than in the IPT group, and higher values at recovery than baseline.

\section{DISCUSSION}

This is the first controlled study to examine the effects of prior fluoxetine administration of EEG sleep in depressed patients. Patients successfully treated with fluoxetine plus IPT showed increases in the percentage of REM sleep and phasic REM, whereas patients successfully treated with IPT alone showed no such increases. There was also a tendency for fluoxetine-treated patients to have increased slow wave sleep at remission, with no change evident in the IPT alone group. These differences in EEG sleep were observed despite the fact that baseline and recovery sleep studies in both groups were conducted when patients were medication-free. There are four potential explanations for this pattern of findings: 1) changes associated with recovery from depression; 2) effects resulting from persistent fluoxetine or its metabolites; 3 ) drug discontinuation (rebound or

Table 2. Clinical and EEG Sleep Measures in FLU and IPT Groups

\begin{tabular}{|c|c|c|c|c|c|c|c|c|c|c|}
\hline \multirow[b]{2}{*}{ Variable } & \multicolumn{2}{|c|}{$\begin{array}{c}\text { IPT + FLU Group } \\
\quad(n=23)\end{array}$} & \multicolumn{2}{|c|}{$\begin{array}{l}\text { IPT Group } \\
\quad(\mathrm{n}=23)\end{array}$} & \multicolumn{2}{|c|}{$\begin{array}{l}\text { Group Effect } \\
\text { (IPT + FLU } \\
\text { vs. IPT) }\end{array}$} & \multicolumn{2}{|c|}{$\begin{array}{c}\text { Time Effect } \\
\text { (Baseline vs. } \\
\text { Recovery) }\end{array}$} & \multicolumn{2}{|c|}{$\begin{array}{l}\text { Group *Time } \\
\text { Interaction } \\
\text { Effect }\end{array}$} \\
\hline & Baseline & Recovery & Baseline & Recovery & $F(d f)$ & $p$ & $F(d f)$ & $p$ & $F(d f)$ & $p$ \\
\hline $\begin{array}{l}\text { Hamilton Rating } \\
\text { Scale for depression }\end{array}$ & $18.2(3.1)$ & $4.2(3.1)$ & $17.8(2.3)$ & $2.7(2.6)$ & $3.11(1,44)$ & .08 & $504.9(1,44)$ & .0001 & $0.71(1,44)$ & 41 \\
\hline Pittsburgh Sleep & & & & & & & & & & \\
\hline $\begin{array}{l}\text { Quality Index }{ }^{a} \\
\text { Slow Wave Sleep }\end{array}$ & $9.5(3.7)$ & $3.9(1.5)$ & $7.9(3.7)$ & $4.3(1.7)$ & $1.04(1,35)$ & .31 & $47.5(1,35)$ & .0001 & $2.36(1,35)$ & .13 \\
\hline $\begin{array}{l}\text { MANOVA } \\
\text { REM Sleep }\end{array}$ & & & & & $1.13(8,37)$ & .36 & $1.29(8,37)$ & .28 & $2.67(8,37)$ & .02 \\
\hline $\begin{array}{l}\text { MANOVA } \\
\text { Sleep Continuity }\end{array}$ & & & & & $1.85(7,38)$ & 11 & $3.02(7,38)$ & .01 & $2.46(7,38)$ & .04 \\
\hline $\begin{array}{l}\text { MANOVA } \\
\text { REM Latency/Delta }\end{array}$ & & & & & $0.72(5,40)$ & .62 & $1.20(5,40)$ & .33 & $1.69(5,40)$ & 16 \\
\hline Ratio MANOVA & & & & & $0.98(2,43)$ & .38 & $0.14(5,40)$ & .87 & $1.41(5,40)$ & .26 \\
\hline
\end{tabular}

${ }^{a}$ Analyses based on complete data in 37 subjects. 


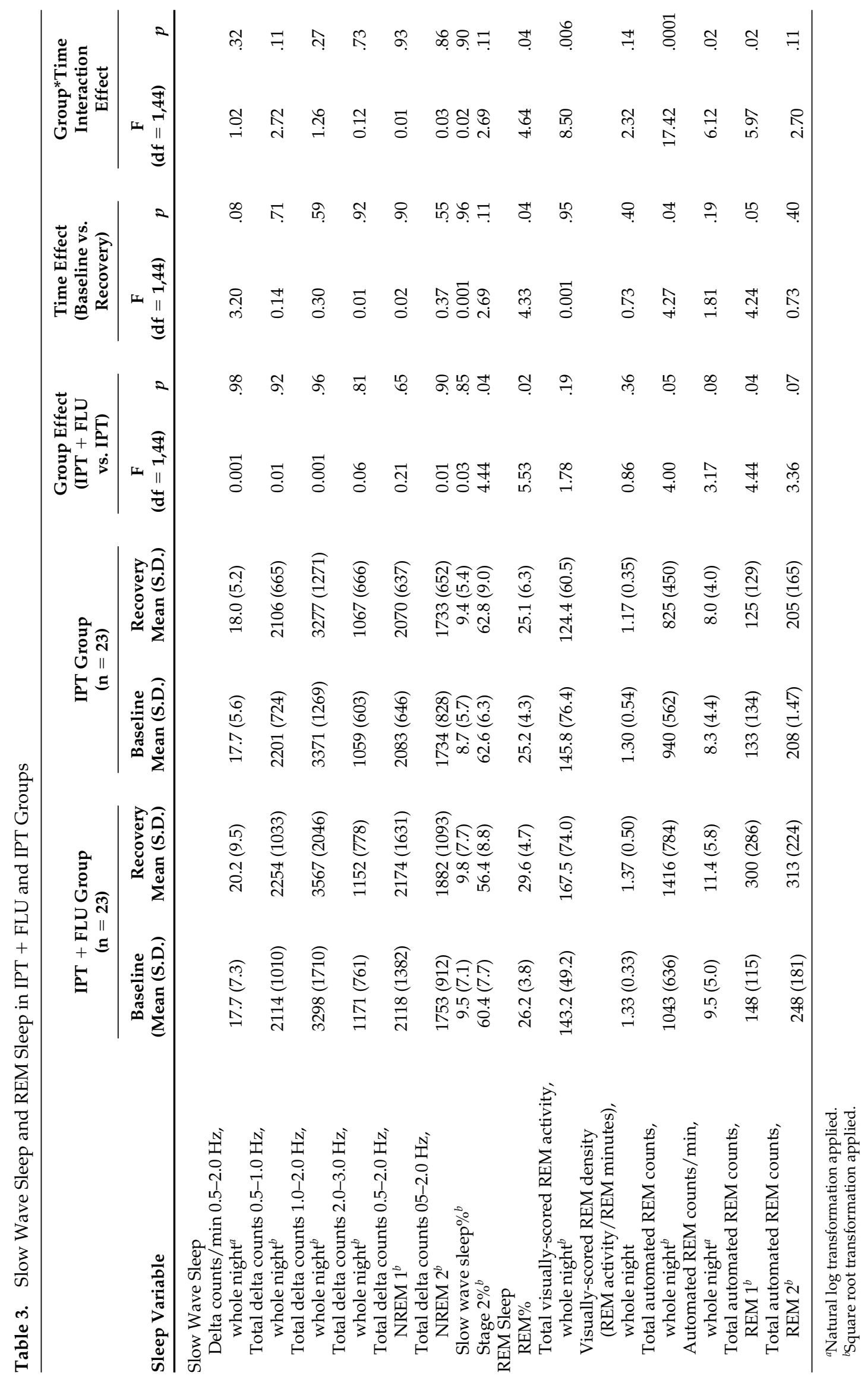




\section{REM SLEEP AT BASELINE AND RECOVERY IN IPT+FLU AND IPT GROUPS}

REM Percent

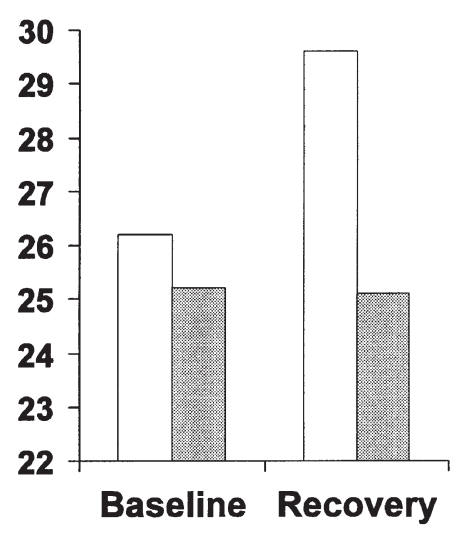

Total REM Counts

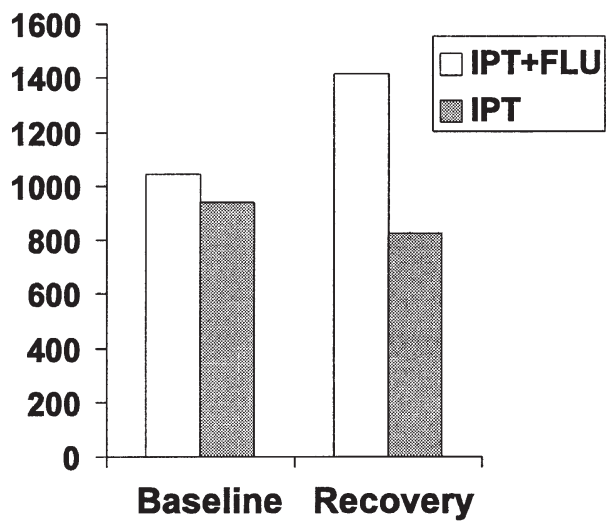

Figure 1. REM percent and total phasic REM counts as identified by computer algorithm for IPT + FLU and IPT groups at baseline and recovery sleep assessments. Significant ANOVA group*time interaction effects were noted for each variable (REM percent $F=4.6$; $d f=1,44$; $p=.04$; REM counts $F=17.4 ; d f=1,44$; $p=.0001)$. withdrawal) effects; and 4) neuroadaptational changes induced by prior fluoxetine exposure.

The different pattern of changes in the IPT + FLU group and the control group of IPT alone patients in our study argues against the possibility that symptomatic improvement alone accounted for the observed changes in EEG sleep. It is also unlikely that the increased tonic and phasic REM in the IPT + FLU group compared to the IPT group resulted from a longer interval between the two sleep studies in the IPT + FLU group. Previous longitudinal studies of EEG sleep in depression have consistently shown a decrease in REM sleep measures from the symptomatic to recovered states in drug-free patients (Thase et al. 1998; Buysse et al. 1992; Riemann and Berger, 1989). Thus, both remission of depression and a longer time interval between presentation and remission would be expected to result in decreased rather than increased REM measures. Likewise, greater depression severity or differences in age or sex cannot explain the significant interactions we observed.

Previous studies have indicated a consistent pattern of EEG sleep changes during fluoxetine treatment compared to drug-free baseline in depressed patients. These changes include reduced REM sleep percentage, slow wave sleep percentage, and sleep efficiency; and increased Stage 1 NREM sleep and wakefulness (Armitage et al. 1997a; Gillin et al. 1997; Hendrickse et al. 1994; Kerkhofs et al. 1990). The number of phasic eye movements during REM sleep is also increased during fluoxetine treatment (Armitage et al. 1995, 1997b; Hendrickse et al. 1994). Thus, the pattern of EEG sleep changes in the IPT + FLU group only partially matched the pattern expected from continued effects of fluoxetine in patients' blood. The long elimination half-life of fluoxetine and its metabolites, which can range from seven to 15 days, could account for some of these findings. We did not measure plasma fluoxetine or norfluoxetine levels at the time of the second sleep studies, but on the basis of their half-lives, it would have been reasonable to expect some measurable drug concentration.

There are fewer data regarding the effects of fluoxetine discontinuation on EEG sleep. Discontinuation of tricyclic antidepressants is associated with rebound increases in the amount of REM sleep (Hartmann and Cravens 1973; Dunleavy et al. 1972; Gillin et al. 1978; Kupfer et al. 1994). The effects of tricyclic antidepressant discontinuation on phasic REM activity sleep are less clear, with evidence for an increase, decrease, or no change compared to the drug administration period (Kupfer et al. 1994; Buysse et al. 1996; Gillin et al. 1978). Discontinuation of citalopram, another SRI drug, leads to rebound of REM sleep amount, but findings with regard to phasic REM activity were not reported (van Bemmel et al. 1993). Controlled studies during fluoxetine discontinuation have not previously been reported, although Schenck and colleagues (1992) reported a single case showing elevated REM sleep percentage and slight reduction of phasic REM two months after fluoxetine discontinuation relative to values on drug. Medication withdrawal effects can occur even with measurable drug levels, because such effects depend on a change in drug levels and drug binding to relevant receptor sites. Thus, findings in the current IPT + FLU group appear to be compatible with drug discontinuation effects except for the increase in phasic eye movements.

One final possibility is that treatment with fluoxetine induces changes in REM sleep regulation that persist beyond the period of detectable blood levels, and be- 
yond an acute withdrawal period. Uncontrolled studies have noted eye movements during NREM sleep which may persist for as long as 19 months after fluoxetine discontinuation (Schenck et al. 1992; Winkelman et al. 1992). Such changes could be viewed as persistent neuronal adaptations to acute changes in serotonergic transmission caused by fluoxetine administration. Persistent changes in serotonergic function have been observed in animal studies with the serotonin-depleting drug fenfluramine (McCann et al. 1997), although there is no evidence from animal or human studies that fluoxetine or other SRI drugs cause similar neurotoxicity.

When considered in the context of these investigations, our results appear to demonstrate a combination of both discontinuation effects (increase in slow wave sleep and tonic REM) and persistent drug effects (increase in phasic REM). This explanation would depend on the presence of distinct regulatory systems for phasic and tonic REM sleep that are differentially sensitive to serotonergic manipulations. Studies of tryptophan depletion in healthy adults provide some support for this possibility. The two published studies in healthy adults showed differential effects of tryptophan depletion on tonic and phasic REM, although the direction of these changes was not consistent across studies (Voderholzer et al. 1998; Bhatti et al. 1998). Total plasma tryptophan after depletion was significantly and negatively correlated with REM density in the study by Bhatti and colleagues (1998). Preliminary results demonstrated an increase in both REM sleep percentage and REM density when a tryptophan- free drink was given to a group of remitted depressed patients treated with serotonin reuptake inhibitor antidepressants (Bhatti et al. 1995). Furthermore, parachlorophenylalanine (PCPA) administration and lesions of the dorsal raphe, both of which decrease serotonin, result in increase in ponto-geniculoocciptal waves, which are closely related to phasic events such as eye movements during REM sleep (Siegel 1994; Mendelson 1987).

Taken together, these studies indicate that acute decreases in serotonergic neurotransmission are associated with increases in REM sleep, and that tonic and phasic REM measures may change independently. These findings also suggest that results in our IPT + FLU patients are consistent with a relative decrease in serotonergic transmission at the recovery sleep evaluation compared to the baseline. However, this explanation is difficult to reconcile with the increase in phasic REM activity also seen with acute administration of fluoxetine and other antidepressants.

Our results have several implications for research and clinical practice. First, the finding of persistent electrophysiological changes after fluoxetine administration may have subtle correlates in patient symptoms. Although our patients reported no unusual symptoms on our usual battery of rating scales, clinicians should be alert to the possibility that some patients may experience subjective correlates of increased REM sleep, such as abnormal dreams or insomnia, on discontinuation of SRI antidepressants (Zajecka et al. 1997). Second, clinicians and researchers should be cautious in assessing patients previously treated with fluoxetine, because they may demonstrate physiological changes for longer than four weeks after drug discontinuation.

The current study had several limitations that can be addressed in future studies. First, we studied only women because of the goals of the parent study. Although there is no reason to believe that men and women will differ in their physiological responses to fluoxetine, we cannot exclude that possibility, particularly when emerging data on estrogen status and SSRI response are considered (Schneider et al. 1997). Second, we did not routinely assess apnea or periodic limb movements. Previous studies have not found a high rate of apnea or periodic limb movements in patients with insomnia or depression, even among the elderly (Vgontzas et al. 1995; Buysse et al. 1996). There is no reason to believe that apnea or periodic limb movements would have been differentially associated with the IPT or IPT + FLU groups at baseline, nor is it likely that these sleep problems could produce the particular pattern of results we found. Third, some of our patients had been treated previously with SRI and other antidepressants. However, the proportion of prior SRI treatment in IPT and IPT + FLU patients was very similar, making this another unlikely confound. Fourth, we did not study EEG sleep during active treatment with fluoxetine, which would have helped to more clearly delineate persistent versus discontinuation effects. Fifth, we did not measure fluoxetine or norfluoxetine levels during the repeat sleep studies, which would again help to address the persistent versus withdrawal question. Finally, it would be illuminating in the future to conduct additional studies more than four weeks after medication discontinuation, in order to better define the duration of fluoxetine's effects on brain function.

\section{ACKNOWLEDGMENTS}

This work was supported by NIH grants MH-30915, MH24652, MH-49115, AG-15138

\section{REFERENCES}

Armitage R, Emslie G, Rintelmann J (1997b): The effect of fluoxetine on sleep EEG in childhood depression: A preliminary report. Neuropsychopharmacology 17:241245

Armitage R, Trivedi M, Rush AJ (1995): Fluoxetine and ocu- 
lomotor activity during sleep in depressed patients. Neuropsychopharmacology 12:159-165

Armitage R, Yonkers K, Cole D, Rush AJ (1997a): A multicenter, double-blind comparison of the effects of nefazodone and fluoxetine on sleep architecture and quality of sleep in depressed outpatients. J Clin Psychopharmacol 17:161-168

Beasley CM, Sayler ME, Weiss AM, Potvin JH (1992): Fluoxetine: Activating and sedating effects at multiple fixed doses. J Clin Psychopharmacol 12:328-333

Beck AT, Ward CH, Mendelson M, Mock J, Erbaugh J (1961): An inventory for measuring depression. Arch Gen Psychiatry 4:561-571

Benca RM, Obermeyer WH, Thisted RA, Gillin JC (1992): Sleep and psychiatric disorders: a meta-analysis. Arch Gen Psychiatry 49:651-668

Bhatti T, Gillin JC, Golshan S, Clark C, Demodena A, Schlossr A, Stahl S, Kelsoe J, Rapaport M (1995): The effect of a tryptophan-free amino acid drink on sleep and mood in normal controls. Sleep Res 24:153

Bhatti T, Gillin JC, Seifritz E, Moore P, Clark C, Golshan S, Stahl S, Rapaport M, Kelsoe J (1998): Effects of a tryptophan-free amino acid drink challenge on normal human sleep electroencephalogram and mood. Biol Psychiatry 43:52-59

Buysse DJ, Frank E, Lowe KK, Cherry CR, Kupfer DJ (1997): Electroencephalographic sleep correlates of episodes and vulnerability to recurrence in depression. Biol Psychiatry 41:406-418

Buysse DJ, Hall M, Tu XM, Land S, Houck PR, Cherry CR, Kupfer DJ, Frank E (1998): Latent structure of EEG sleep variables in depressed and control subjects: descriptions and clinical correlates. Psychiatry Res 79:105-122

Buysse DJ, Kupfer DJ, Frank E, Monk TH, Ritenour A, Ehlers CL (1992): Electroencephalographic sleep studies in depressed patients treated with psychotherapy. II. Longitudinal studies at baseline and recovery. Psychiatry Res 40:27-40

Buysse DJ, Reynolds CF, Hoch CC, Houck PR, Kupfer DJ, Mazumdar S, Frank E (1996): Longitudinal effects of nortriptyline on EEG sleep and the likelihood of recurrence in elderly depressed patients. Neuropsychopharmacology 14:243-252

Buysse DJ, Reynolds CF, Monk TH, Berman SR, Kupfer DJ (1989): The Pittsburgh Sleep Quality Index (PSQI): A new instrument for psychiatric research and practice. Psychiatry Res 28:193-213

Dew MA, Reynolds CF, Houck PR, Hall M, Buysse DJ, Frank E, Kupfer DJ (1997): Temporal profiles of the course of depression during treatment: Predictors of pathways toward recovery in the elderly. Arch Gen Psychiatry 54:1016-1024

Doman J, Detka C, Hoffman T, Kesicki D, Monahan JP, Buysse DJ, Reynolds CF, Coble PA, Matzzie J, Kupfer DJ (1995): Automating the sleep laboratory: Implementation and validation of digital recording and analysis. Intl J Med Inform 38:277-290

Dorsey CM, Lukas SE, Cunningham SL (1996): Fluoxetineinducted sleep disturbance in depressed patients. Neuropsychopharmacology 14:437-442
Dunleavy DLF, Brezinova V, Oswald I, MacLean AW, Tinker M (1972): Changes during weeks in effects of tricyclic drugs on the human sleep brain. Br J Psychiatry 120:663-672

Endicott J, Spitzer RL (1978): A Diagnostic Interview. The schedule for affective disorders and schizophrenia. Arch Gen Psychiatry 35:837-844

Endicott J, Spitzer RL, Fleiss JL, Cohen JL (1976): The global assessment scale. A procedure for measuring overall severity of psychiatric disturbance. Arch Gen Psychiatry 33:766-771

First M, Spitzer RL, Gibbon M, Williams JBW (1995): Structured Clinical Interview for DSM-IV Axis I DisordersPatient Edition (SCID-I/P). Version 2.0 ed. New York, NY, New York State Psychiatric Institute

Giles DE, Jarrett RB, Roffwarg HP, Rush AJ (1987): Reduced rapid eye movement latency: A predictor of recurrence in depression. Neuropsychopharmacology 1:33-39

Gillin JC, Rapaport M, Erman MK, Winokur A, Albala BJ (1997): A comparison of nefazodone and fluoxetine on mood and on objective, subjective, and clinician-rated measures of sleep in depressed patients: A doubleblind, 8-week clinical trial. J Clin Psychiatry 58:185-192

Gillin JC, Wyatt RJ, Fram D (1978): The relationship between changes in REM sleep and clinical improvement in depressed patients treated with amitriptyline. Psychopharmacology 59:267-272

Hamilton M (1967): Development of a rating scale for primary depressive illness. Br J Soc Clin Psychol 6:278-296

Hartmann E, Cravens J (1973): The effects of long term administration of psychotropic drugs on human sleep: III. The effects of amitriptyline. Psychopharmacology 33:185-202

Hendrickse WA, Roffwarg HP, Grannemann BD, Orsulak PJ, Armitage R, Cain JW, Battaglia J, Debus JR, Rush AJ (1994): The effects of fluoxetine on the polysomnogram of depressed outpatients: A pilot study. Neuropsycho pharmacology 10:85-91

Kerkhofs M, Rielaert C, de Maertelaer V, Linkowski P, Czarka M, Mendlewicz J (1990): Fluoxetine in major depression: Efficacy, safety and effects on sleep polygraphic variables. Int Clin Psychopharmacol 5:253-260

Klerman GL, Weissman MM, Rounsaville BJ, Chevron E (1984): Interpersonal Psychotherapy of Depression. New York, NY, Academic Press, Basic Books Inc

Kupfer DJ, Frank E, McEachran AB, Grochocinski VJ (1990): Delta sleep ratio: A biological correlate of early recurrence in unipolar affective disorder. Arch Gen Psychiatry 47:1100-1105

Kupfer DJ, Pollock BG, Perel JM, Miewald JM, Grochocinski VJ, Ehlers CL (1994): Effect of pulse loading with clomipramine on EEG sleep. Psychiatry Res 54:161-175

Lauer CJ, Pollmacher T (1992): On the issue of drug washout prior to polysomnographic studies in depressed patients. Neuropsychopharmacology 6:11-16

McCann UD, Seiden LS, Rubin LJ, Ricaurte GA (1997): Brain serotonin neurotoxicity and primary pulmonary hypertension from fenfluramine and dexfenfluramine. JAMA 278:666-672

Mendelson WB (1987): Pharmacology and neurotransmitters 
in sleep. In Anonymous, Human Sleep-Research and Clinical Care. New York, NY, Plenum Publishing Corporation, pp 33-79

Nicholson AN, Pascoe PA (1988): Studies on the modulation of the sleep-wakefulness continuum in man by fluoxetine, a 5-HT uptake inhibitor. Neuropharmacology 27: 597-602

Raskin A, Schulterbrandt J, Reatig N, McKeon JJ (1969): Replication of factors of psychopathology in interview, ward behavior and self-report ratings of hospitalized depressives. J Nerv Ment Dis 148:87-98

Riemann D, Berger M (1989): EEG sleep in depression and in remission and the REM sleep response to the cholinergic agonist RS 86. Neuropsychopharmacology 2:145152

Saletu B, Frey R, Krupka M, Anderer P, Grunberger J, See WR (1991): Sleep laboratory studies on the single-dose effects of serotonin reuptake inhibitors paroxetine and fluoxetine on human sleep and awakening qualities. Sleep 14:439-447

Satterlee WG, Faries D (1995): The effects of fluoxetine on symptoms of insomia in depressed patients. Psychopharmacol Bull 31:227-237

Schenck CH, Mahowald MW, Kim SW, O'Connor KA, Hurwitz TD (1992): Prominent eye movements during NREM sleep and REM sleep behavior disorder associated with fluoxetine treatment of depression and obsessive-compulsive disorder. Sleep 15:226-235

Schneider LS, Small GW, Hamilton SH, Bystritsky A, Nemeroff CB, Meyers BS, Fluoxetine Collaborative Study Group (1997): Estrogen replacement and response to fluoxetine in a multicenter geriatric depression trial. Am J Ger Psychiatry 5:97-106

Sharpley AL, Cowen PJ (1995): Effect of pharmacologic treatments on the sleep of depressed patients. Biol Psychiatry 37:85-98

Siegel JM (1994): Brainstem mechanisms generating REM sleep. In Kryger MH, Roth T, Dement WC (eds), Principles and Practice of Sleep Medicine, 2nd ed. Philadelphia, PA, W.B. Saunders Company pp 125-144

Spitzer RL, Williams JB, Gibbon M, First MB (1992): The
Structured Clinical Interview for DSM-III-R (SCID). I: History, rationale, and description. Arch Gen Psychiatry 49:624-629

Spitzer, RL, Williams, JBW, Gibbon, M, First, MB (1988): Structured Clinical Interview for DSM-III-R: Patient Version (SCID-P, 6/01/88). New York, NY, Biometrics Research Department

Stokes PE (1995): The potential role of excessive cortisol induced by HPA hyperfunction in the pathogenesis of depression. Eur Neuropsychopharmacol 5(suppl):77-82

Thase ME (1998): Depression, sleep, and antidepressants. J Clin Psychiatry 59:55-65

Thase ME, Fasiczka AL, Berman SR, Simons AD, Reynolds CF (1998): Electroencephalographic sleep profiles before and after cognitive behavior therapy of depression. Arch Gen Psychiatry 55:138-144

van Bemmel AL, Van den Hoofdakker RH, Beersma DG, Bouhuys AL (1993): Changes in sleep polygraphic variables and clinical state in depressed patients during treatment with citalopram. Psychopharmacology 113: 225-230

Vgontzas AN, Kales A, Bixler EO, Manfredi RL (1995): Usefulness of polysomnographic studies in the differential diagnosis of insomnia. Int J Neurosci 82:47-60

Voderholzer U, Hornyak M, Thiel B, Huwig-Poppe C, Kiemen A, Konig A, Backhaus J, Riemann D, Berger M, Hohagen F (1998): Impact of experimentally induced serotonin deficiency by tryptophan depletion on sleep EEG in healthy subjects. Neuropsychopharmacology 18:112-124

von Bardeleben U, Steiger A, Gerken A, Holsboer F (1989): Effects of fluoxetine upon pharmacoendocrine and sleep-EEG parameters in normal controls. Int Clin Psychopharmacol 4:1-5

Winkelman J, Dorsey C, Cunningham S, Lukas S, Richardson $G$ (1992): Fluoxetine produces persistent rapid eye movements in non-rem sleep. Sleep Res 21:78

Zajecka J, Tracy KA, Mitchell S (1997): Discontinuation symptoms after treatment with serotonin reuptake inhibitors: A literature review. J Clin Psychiatry 58:291-297 